ЧЕРНЫШОВ Алексей Геннадиевич - доктор политических наук, профессор кафедры государственного и муниципального управления Финансового университета при Правительстве РФ (125993, Россия, г. Москва, Ленинградский пр-кт, 49; ag555@таil.ru)

\title{
РОДИТЕЛИ КАК ГРАЖДАНЕ
}

Аннотация. В статье предпринята попытка проанализировать феномен развития родительства как особой социальной общности людей, показать важность превращения родителя в полноценного гражданина, способного бороться за свои права, формировать и отстаивать созидательные программы развития. Кроме того, автор высказывает мысль о необходимости формирования глобального интернационального гражданского родительского форума.

Ключевые слова: родители, семья, граждане, неграждане, полуграждане, глобальный родительский форум

$\mathrm{C}$ амо понятие «родители», кажется, не требует особого пояснения ввиду очевидности. Для каждого человека смысл этого слова с детства знаком и понятен, даже в том случае, если настоящие биологические родители того или иного ребенка по каким-то причинам не занимаются воспитанием своего чада и не живут с ним рядом. Родители - это ближайшие родственники, составляющие основу его семьи. Прежде всего, это отец и мать, а в русской традиции вообще предки ${ }^{1}$. Также можно сказать, что родители - это лица (отец и мать), записанные в книге записей рождений в качестве таковых в отношении определенного ребенка, хотя юридическое и фактическое понятие родителя может не совпадать с биологическим ${ }^{2}$.

В социальном формате практик мы больше привыкли оперировать понятием «семья». К настоящему времени выработаны законодательные нормы понимания полной и неполной, традиционной и нетрадиционной семьи. Однако важно оценить складывающуюся общность не только через семейные институты, а через понимание родителя как такового, т.е. конкретного индивида, у которого в настоящее время может даже и не быть собственных детей и супруги, но при этом у него могут быть отец и мать, какие-то другие родственники. Форматы семейных практик могут быть самыми разнообразными, но сегодня они порой не отвечают на все вопросы, которые ставит перед нами современная действительность. Также представляется крайне актуальным оценить роль и значение понятия «родитель» не просто применительно к конкретной семье, а именно как возможности формирования определенной родительской общности интересов, не зацикливаясь при этом на вопросах воспитания и образования, которые в той или иной степени должны быть присущи каждой семье, в которой есть дети (это не предмет нашего исследования), а показывая родителя как гражданина с его правами и ответственностью не только относительно своего ребенка, но и социума, в котором он живет и формируется.

Такой анализ становится насущной потребностью именно сейчас, когда на мир давят глобальные тенденции, разрушая и видоизменяя до неузнаваемости прежний ареал человека.

Родителя априори можно и нужно рассматривать как биологическое существо. В этом плане мужское и женское начала дают жизнь новым членам человеческого сообщества, выступают в формате передачи определенных традиций,

\footnotetext{
${ }^{1}$ https://dic.academic.ru/dic.nsf/lower/18011.

2 https://ru.wikipedia.org/wiki/\%D0\%A0\%D0\%BE\%D0\%B4\%D0\%B8\%D1\%82\%D0\%B5\%D0\%BB\%D $0 \% \mathrm{~B} 8$
} 
являются носителями определенного генетического кода и пр. Исследовать феномены и парадоксы, возникающие в данном разрезе, необходимо. И такие исследования периодически проводятся.

Человек, безусловно, - существо общественное. И, вырастая из биологического, он формирует различные человеческие общности и институты. При этом, заметим, глобализация не просто разрывает на части прежние устои и традиции, но и делает совершенно нежизнеспособными многие ранее существовавшие социально-политические конструкции и скрепы. Можно уже воочию наблюдать кризис системы выборов, таких институтов, как парламент, партии, профсоюзы, церковь, семья. Да и кризис социального государства 1 набирает свои обороты. Но, как говорится, свято место пусто не бывает. Вакуум должен быть чем-то заполнен. Пришедшая в нашу жизнь «цифра» вместе с окутавшей большинство развитого сообщества Всемирной паутиной лишь ускорили и как бы виртуально сблизили контакты между людьми. Однако данные технологии пока не стали возможностью для коллективной выработки образа будущего, причем будущего не киборгов и роботов, а именно сохранившихся и развивающихся настоящих, живых homo sapiens. Более того, они привели к появлению на свет феномена отвлеченного родительства ${ }^{2}$, сказывающегося на качестве взаимоотношений родителей с детьми (это когда, например, главному в жизни российских мужчин, а именно российским женщинам и своим детям, они уделяют в среднем 45 мин в сутки; виртуальной же реальности социальным сетям, просмотру телевизоров, компьютеров, гаджетов - от 4 до 7 ч) ${ }^{3}$.

Тем не менее происходит кардинальная смена вех с точки зрения понимания роли и места родителей в социальной иерархии и гражданской ответственности не просто за своих детей, но и за выработку общей повестки дня на будущее.

Родители как конкретные индивидуумы все больше «вываливаются» из семейного «пазла» и начинают претендовать на самостоятельную роль нового глобального игрока.

Прежние социальные конструкции, которые объединяли «семейных» людей по определенным темам и проблемам, продолжают существовать и даже развиваться, трансформируясь в те или иные формы общественного действия. Тут и Комитет солдатских матерей ${ }^{4}$, и Всероссийское родительское собрание 5 , и «Бессмертный полк» 6 , и многие другие. Однако сегодня это движение подчас уже не олицетворяет собой некие семейные ценности, а объединяет людей по более широкому спектру гражданских вопросов, в т.ч. политической направленности. При этом, и это одна из характерных примет дня нынешнего, за ростом разрыва между богатыми и бедными слоями общества, за попыткой вернуться к сословному принципу формирования создается как бы два слоя понимания родительства как «класса». С одной стороны, это попытка осмыслить, а затем и выстроить руками родителей, устремленных в созидательное будущее, «стратегию гражданской самоорганизации» [Розов 2011]. С другой стороны, это нарас-

\footnotetext{
${ }^{1}$ Сахнин А. Кризис эпохи демонтажа социального государства. - Эксперт. 29.10. 2018. № 44. Доступ: http://expert.ru/expert/2018/44/krizis-epohi-demontazha-sotsialnogo-gosudarstva; Обухова Е., Пахунов К. Социальное государство прощается с вами. - Эксперт. 29.10.2018. № 44. Доступ: http://expert.ru/ expert/2018/44/sotsialnoe-gosudarstvo-proschaetsya-s-vami

2 Журенков К. Прилипли к экранам. Как вредят человеку гаджеты и интернет. - Огонек. 12.11.2018. № 43. С. 4. Доступ: https://www.kommersant.ru/doc/3778535

3 Малинецкий Г. Вся цифровая экономика должна быть выброшена как целое. 30.06.2018. Доступ: https://cont.ws/@proc79/991336

4 http://ksmrus.ru

5 http://www.oodvrs.ru/

6 http://www.moypolk.ru/
} 
тающая лавина проблем с теми представителями родителей из «сильных мира сего», у которых, как им кажется, уже все вопросы для них самих и их детей решены в настоящем, и будущее - «излишне». Понятно, что прежде всего речь идет о финансовой сверхдостаточности, когда многим детям ничего не остается, как стать «прожигателями жизни», тем самым подтвердив тенденцию происходящего сдвига от воспитательной этики долга к этике удовольствия [Фуко 2008]. Родители же богатых отпрысков стерегут свое кресло и должность, пытаясь извлечь из него как можно больше ренты. В этом смысле многие представители данной категории родителей вместе со своими детьми ментально и физически находятся вне ценностных ориентаций большинства населения, проживающего на конкретной территории. Сегодня очень многие дети богатейших олигархов и политиков не имеют ничего общего с Россией ${ }^{1}$, разве что помогают зарабатывать своим предкам на родине очередные миллионы и миллиарды. И в этой иерархии ценностей никакими патриотами такие дети стать не могут, потому что просто-напросто не видят себя гражданами. Происходит же это прежде всего потому, что старшие не видят и не хотят прогнозировать созидательный образ будущего даже для своих детей. И эти, с позволения сказать, молодые космополиты как «современные революционеры оказываются интернационалистами: мертвые в любви, они лишены и родины» [Ильин 2006: 14]. И даже те, кто остается жить в России, ведут праздный и паразитический образ жизни ${ }^{2}$. Но все ли представители подрастающего поколения готовы смириться с тем, что их родители оставят им в наследство «мусорную» планету? Хотя никто и не спрашивает их мнения. Старшее поколение пытается сделать им «подарок», от которого невозможно будет отказаться. Так, родители, особенно из высшего бомонда, стараются пожить для себя.

Фактически получается, что власть, олицетворяющая государство, в рамках «своего» поколения живет его производными, держится мертвой хваткой за его каноны и устои, дабы их не раскачали. А то, что жизнь не стоит на месте и меняется, это им как-то невдомек. В итоге оказывается, что все больше граждан-родителей начинают с недоверием относиться к своему собственному государству. Ведь «страна» и «государство» - это «придуманные нами понятия; они придуманы для нашего удобства и должны нам служить - других задач у них нет и быть не может. Те, кто полагает, что ментальные конструкты могут жить сами по себе и еще требовать чего-то от реальных людей, серьезно задержались в социальном развитии - где-то на уровне примитивных родоплеменных религий с их антропоморфическими анимизмами» ${ }^{3}$.

Родительское сообщество сегодня фактически отстранено государством, причем по-бюрократически насильно и демонстративно, от того, чтобы участвовать в разработке программ развития для своих детей. За них это делают чиновники. И складывается ощущение, что у самой номенклатуры нет детей 4 .

Власть фактически собственными действиями разорвала негласные догово-

1 Дмитриев И. Наследники миллиардов. 13.08.2018. Доступ: https://versia.ru/deti-bogatejshixoligarxov-ne-imeyut-nichego-obshhego-s-rossiej html

2 https://www.mk.ru/incident/2018/08/12/smi-syna-eksglavy-cos-fsb-zaderzhali-za-torgovlyu-narkotikami.

3 Мовчан А. За ваши и наши налоги. Кто кому должен в отношениях российского общества и государства. 21.11.2018. Доступ: https://carnegie.ru/commentary/77751 - https://carnegie.ru/ commentary/77751?utm_source $=$ rssemail\&utm_medium $=$ email\&mkt_tok $=$ eyJpIjoiT 1 RReE4ySTJPRGMx TWpWaiIsInQiOiJcL00wREhiU1pGSG52Szl4dGY G2KzJqT0hLOUxyOStmSHRtUmx1VzFyT3FYZ2wzK3V IOHMxcGloMmdOQ2o0Ynpjc2pkTHVxck5qYkRLWmpGczh6d29ZQ3NOWUxQUkRyUExFUUE5QmNia DhTbEpDbzU4MStDKzNINzM3eCsyY2hsenoifQ\%3D\%3D

4 https://www.eg.ru/society/556601/ 
ренности, когда согласие граждан на неучастие в политике компенсировалось невмешательством государства в их частную жизнь.

Закон об образовании в Российской Федерации ${ }^{1}$ дал родителям право самим воспитывать своих детей, вне школы, на индивидуальном обучении. Но что это право означает на деле? Забирайте и «валите»? Это означает разрушить школьный социум [Пол 2015] вместо того, чтобы кропотливо заниматься его встраиванием в современные реалии, в то время как следует формировать и обнародовать самые ценные педагогические практики (где и кем это было сохранено и предложено учительскому и родительскому сообществу для обсуждения и применения?), убрать бюрократию и формализм, учить детей на реальных примеpax, которым можно было бы подражать и перенимать бесценный опыт, любить детей не теоретически, а воспитывать своим примером. Дети ведь копируют нашу жизнь. Они просто ее запоминают в самом раннем детстве и потом воспроизводят. Если в основе лежат идеи разумного воспитания [Дрейкурс, Золц 2015], значит, важно продвигать завет мудрого родителя: не делать никому того, что сам себе не желаешь [Честерфилд 2010: 195].

Сегодняшние же реформы направлены на то, чтобы «остановить образование, сузить умственный кругозор. Не дать никакого направления мысли. И какое же это счастье при полном невежестве» [Лесков 1957]. Поэтому разбегутся родители - власти только облегчение, потому что исчезнет еще одна точка социализации, а значит и возможность формирования критической массы и протеста. А так одинокие родители - «полуграждане». В такой ситуации становится важным научиться объединяться в неструктурированном, неинституциональном пространстве, так понятном бюрократии. Она и сама то хочет обособиться по сословному принципу ${ }^{2}$ и жить в своем мире, тихой заводи за высокими заборами с охраной. Не понимает, что бумеранг обязательно вернется и вызовет обратное «родительское гражданское сопротивление» 3 . Россия сделала скачок в развитии через массовое образование в XX в. Сейчас глобальная элита отыгрывает назад, заставляя «местечковых» правителей превратить образование из общей практики в элитарное, т.е. не для каждого, причем ограниченное, прежде всего, в силу финансовых возможностей, чтобы право учиться имели не самые способные, а самые обеспеченные. Это возврат к мракобесию (Н. Лесков). Сегодняшняя практика поступления в высшие учебные заведения путем сдачи ЕГЭ подтверждает тот красноречивый факт, что на платное отделение могут поступить абитуриенты с практически нулевым результатом по ЕГЭ.

В этих условиях родительство как таковое все больше приобретает политическое, гражданское измерение. «Гражданское родительство» - это отношение не только к своим, но и к чужим детям как к общей ценности [Майофис, Кукулин 2010: 7]. Происходит формирование гражданского родительского сознания. Этот феномен родительства как ценности требует особого и более глубокого исследования.

Если родители, даже без фактически закрепленного юридического статуса, объединяются - это мощная сила. С этой силой власти очень сложно взаимодействовать и создавать прокрустово ложе лояльности. Родители, как тот самый летучий голландец, одновременно и тут, и там. Им не запретишь выйти на улицу и провести несанкционированный митинг и обменяться мыслями вслух. Каждодневно родители ведут или везут детей в школу или детский сад, гуляют

\footnotetext{
1 Федеральный закон от 29.12.2012 N 273-Ф3 «Об образовании в Российской Федерации» (с изм. от 2018 г.). Доступ: http://zakon-ob-obrazovanii.ru/

2 https://www.vedomosti.ru/opinion/articles/2018/07/27/776692-soslovnaya-rossiya?utm_campaign=news paper_27_07_2018\&utm_medium=email\&utm_source=vedomosti

3 Родительское всероссийское сопротивление РВС. Доступ: http://rvs.su; http://katyusha.org
} 
со своими малышами на улице. И никто не может воспрепятствовать такому общению и нарушить канал передачи информации друг от друга. К тому же есть и интернет-коммуникации, пока еще не подвластные тотальному контролю.

При объединении родителей на основе социально и политически значимых целей во многом может стираться грань между богатыми и бедными родителями. Это ли вам не социальная общность нового типа? Причем родители могут объединяться на горизонтальном уровне и в межгосударственном пространстве, если речь идет о будущем их детей. А это все больше вопросы питания, экологии, профилактики заболеваний, качественности образования, т.е. темы без всяких специфических политических или иных программ, понятные всем думающим родителям и заботящимся о том, чтобы вырастить здоровое во всех смыслах потомство [Мэтьюз 2016].

В этом смысле, как мы уже отмечали, родительство как отдельный феномен отличается по многим своим позициям от того, что принято понимать как семейный социум. В данном контексте мы не рассматриваем семью как таковую, но она незримо присутствует в той части, где эта проблематика стыкуется с вышеописанными проблемами родительства. Это осмысление сложностей и «разборок» между родственниками, когда кровные связи порой не способствуют формированию общих мировоззренческих позиций; это потребность в понимании того, что современный родитель обязан сам, без помощи школы и государства, быть профессиональным воспитателем - у него просто нет иного выхода, и что «за прекрасное будущее своего чада отвечаете именно Вы, а не какие-то чужие тети и дяди» [Максимов 2016]. И это гражданская и патриотическая позиция человека, вырастающая не всегда напрямую из отдельно взятой семьи.

И если мы попытаемся более глубоко понять феномен гражданского родительства, нам, безусловно, никуда не уйти от первооснов формирования поколенческого социума [Ядов и др. 2005].

В чем главное предназначение родителей, и кого вообще можно назвать родителем? Смысл: передать свои гены потомкам, зачать новое поколение. Дарим клетки другим. Как животные? Нет, еще и вырастить, воспитать, передать ценностные знания и умения. Если их не передавать, то общество деградирует и вернется в варварство. А на горизонте уже роботы. С одной стороны, созданные человеческим гением, но, с другой - без оценки нравственных, культурных и социальных последствий ${ }^{1}$. В итоге оказывается, что люди «расплодились»они мешают элите беззаботно жить в условиях нарастающей нехватки ресурсов. И, как следствие, нивелируется ценность самой человеческой жизни. И вместо признания того, что «человек - это звучит гордо» ${ }^{2}$, кристаллизуется иная властная доктрина: сужение и уничтожение гражданских прав и человека как личности и превращение его в «пушечное мясо», потому что политическому бомонду приятнее общаться через охрану с лояльными и «проверенными» кадрами, да и вообще генерируется мысль о замене живых и несговорчивых граждан роботами. Кто из родителей, искренне любящих своих детей, может на такое развитие событий подписаться?

В условиях нарастания информационных потоков и способности власти к манипулированию сознанием масс люди пытаются искать «правду жизни» в истории, у своих предков. Ведь и родитель - от слова «род». С одной стороны, власть всячески поддерживает подобные начинания по «возвращению» собственного народа в исторические дебри, при этом густо «смазывая маслом»

\footnotetext{
1 Кувшинова О. Один робот заменяет три рабочих места. - Ведомости. 21.05.2017. Доступ: https:// www.vedomosti.ru/economics/articles/2017/05/22/690779-robot-ekonomike

2 Монолог Сатина. См. Горький М. На дне. 1902 г.
} 
дорогу в прошлое, чтобы легче было там затеряться. При этом она «помогает» узнать не реальную историю и конкретные исторические судьбы, а былинную, сказочную, приукрашенную и выгодную для властей предержащих. Возникает диссонанс. С одной стороны, у людей подогрето желание узнать больше об истории своей семьи, о своих предках, своем роде. С другой стороны, власть всячески потакает лишь попыткам обратиться к героическим страницам истории, погружает в нужные исторические сюжеты и тут же вытаскивает обратно. Все другие поползновения, направленные на получение истинных знаний о прошлом, без домыслов и мифов, власть фактически торпедирует. Людьми, лишенными своих корней, своего рода-племени, легче управлять и манипулировать. А вот знание реальной истории власти не нужно, ибо граждане могут начать задавать очень неприятные вопросы, связанные с тем, за что их родители погибли в тюрьмах в период репрессий или почему за период Великой Отечественной войны страна понесла такие неисчислимые жертвы? И, «веря, что решающий вклад в величие России внес склонившийся над картой Сталин, мы не должны спрашивать, где тот “русский миллиард”, который должен был народиться к концу XX века по прогнозам дореволюционных демографов»1.

Такое поведение политических властей и экономических акторов можно объяснить и другим: многие их представители, сами без роду-племени, оказались на властной и финансовой вершине случайно, по стечению обстоятельств или мошенническим способом.

В отличие от Запада, Россия только нащупывает связь с прошлым. Явственно обозначился новый тренд: у самых обычных россиян появился интерес к истории своей семьи, который базируется не на меркантильной, а на ценностной почве ${ }^{2}$. Но всегда ли рядовым гражданам нужно так глубоко копаться в прошлом, в том числе и искать корни своих предков? Что, собственно, мы хотим найти в архивных залежах и понять? Играет роль пропаганда? Не хватает собственной самоидентификации и точек роста современным родителям? Ведь нужно быть готовым и к тому, что можно такие в своей родословной «скелеты в шкафу» раскопать 3 ! При этом обсуждение модных ныне тем про родовое сознание, генетическую память и наше кровное родство в прошлом подчас не ведут нас к обретению какой-то истины в настоящем. Значит, нужно жить и пытаться выстроить общество ответственных за свою судьбу граждан в настоящем. Не жить одним днем, как многие представители правящего бомонда, но с учетом реальной истории идти в будущее, а не «зависать» все время в прошлом, в красивых обрядах и ритуалах. В нем легче находиться, каким бы трагическим оно ни было, потому что оно уже не требует наших действий. Активного гражданина-родителя ждет настоящее! А сама по себе история, особенно в «стерильном» виде и былинном исполнении, как писал русский ученый Василий Ключевский, ничему не учит, а только наказывает за незнание уроков 4 . Это еще раз подтверждает мысль, что творить нужно в настоящем, лишь опираясь на правду о прошлом и накапливая смысловой потенциал на будущее.

\footnotetext{
1 Терентьев Д. Всю правду знает только народ. Почему фронтовые дневники совсем не похожи на кино о войне. 05.05.2018. Доступ: http://argumenti.ru/society/2018/05/571690

2 Денисенко К., Скоробогатый П. Золотая родословная. - Эксnерm. 2018. № 17-19. 23.04-13.05.

3 Родословная известного русского и советского живописца К.С. Петрова-Водкина: прадед художника был известным разбойником, а дед - сапожник Петр - известным на весь Хвалынск (город в Саратовской области) пьяницей, за что его прозвали Водкиным (в итоге детей Петра звали то Петровыми, то Водкиными, так и закрепилась двойная фамилия). Однажды Петр Водкин зарезал собственную жену и сам умер. А его сын, отец живописца, после такой трагедии стал единственным сапожником в Хвалынске, в рот не бравшим водки. Доступ: https://www.kp.ru/daily/26869/3911823/ (проверено 16.08.2018).

4 https://eksmo.ru/interview/15-aforizmov-vasiliya-klyuchevskogo-ID4418458
} 
Родители зачастую в своих мыслях и поступках живут прошлым и временами своей молодости. Молодежь хочет видеть будущее и перспективы. Если им начинают «перекрывать кислород» в этом стремлении постичь себя, то наступает «ломка сознания» - месть молодого поколения своим родителям за их «поруганное настоящее».

Летаргию, в которую погружается Россия, может предотвратить только приход во взрослую жизнь по-новому думающих и действующих поколений. Только созидательная, рефлексирующая элита вместе с национально ориентированным лидером может оценить перспективы и выстроить для себя и потомков перспективное будущее, при этом самой остаться современной и интересной для новой поколенческой группы, приходящей на смену старой. Поэтому одной из главных политических проблем современности является, в строгом смысле слова, политика нас самих (М. Фуко) - действия сознательных, критически мыслящих граждан, способных создавать горизонтальные связи и объединяться для защиты своих интересов независимо от намерения властей, а порой - и вопреки утвержденным в высоких кабинетах постулатам и красивым речам, льющимся с высоких трибун ${ }^{1}$.

Главное только, чтобы лень ума и вялость воли не овладела самими гражданами. Современный родитель должен отличать трэш ${ }^{2}$ от реальных ценностей, которые нужно отстаивать в настоящем вместе со своими детьми и сподвижниками, и понимать, что оставить в настоящем, а что отправить в прошлое. И нужны реальные последователи, овладевшие опытом и знаниями конкретных процессов и дел. Иначе все призывы к каким-то действиям будут тщетными.

И потребность в этих действиях родители должны культивировать в своих детях с раннего детства. Не подсовывать им планшет или гаджет, чтобы не мешали самим заниматься бытовыми делами и отдыхать. Иначе они будут уходить в виртуальные миры, что заканчивается для ребенка (а потом и взрослого человека) поиском дополненной реальности. А он должен быть рядом, в этом реальном мире, где нужен настоящий думающий человек с выраженной гражданской позицией и волевым критическим мышлением.

Мировая история не может развертываться сразу в нескольких нетождественных сосуществующих мирах. В ней ничто не начинается с чистого листа. Советский эксперимент это прекрасно показал. Но он же показал возможность альтернатив, проектов в рамках четко очерченных границ, заданных объективно существующими политическими, социальными, экономическими и иными реалиями. Не искать таинственные метафизические потенции, а видеть альтернативы в реальных исторических обстоятельствах - вот что могут сделать родители, по-настоящему верящие в силу созидательного начала своих детей. Они должны быть способными к критической оценке той цены [Чернышов 2013], которую нужно заплатить в настоящем, чтобы построить желанное будущее для большинства, основанное на нравственном императиве, а не на прибыли как единственной норме ценности.

Борьба за собственное настоящее и будущие поколения все больше перетекает в русло гражданских инициатив тех родителей, кто желает идти в ногу со временем и сохраниться в качестве свободных личностей. И здесь важно осознание и понимание необходимости движения от техногенной к социогумани-

1 http://carnegie.ru/commentary/?fa=69965\&mkt tok=eyJpIjoiWXpKbU1qazJOVFZpWVRrNSIsInQiO iJhWVBhYmZQajB0eWRQclQrWX1ZTml6YINDbUhWOTA5NVRHWHZtZFwvZjZYY2FZandBVFREWG 5Nbm15VUJmN0FLYWtMN244WE9oYndTV2U1U1NFaEErZ1JrZitjRVVcL0JuK3dZRVRuSkhCSisyYVFM U3luOVhNQ0xSYnRneHh6d3FnIn0

2 Трэш (trash - англ.) - хлам, мусор, бардак; вещь, которая сейчас не актуальна. 
тарной цивилизации, построения саморазвивающихся систем и глобального интернационального гражданского (вне политических границ) родительского форума [Гросс-Ло 2014]. В основе этих преобразований должен быть настоящий ответственный родитель-гражданин. Это может быть шансом сформировать новую глобальную социально-политическую общность и попытаться изменить существующую реальность.

\section{Список литературы}

Гросс-Ло К. 2014. Родители без грании. М.: Синдбад. 368 с.

Дрейкурс Р., Золц В. 2015. Манифест счастливого детства. Основные идеи разумного воспитания. Екатеринбург: Рама Паблишинг. 296 с.

Ильин И.А. 2006. Поющее сердие. М.: Мартин. 256 с.

Лесков Н.С. 1957. Кадетский монастырь. - Собрание сочинений. М.: Художественная литература. 686 с.

Майофис М., Кукулин И. 2010. Новое родительство и его политические аспекты. - Pro et Contra. T. 14. № 1-2. С. 6-19.

Максимов А.М. 2016. Родители как враги. СПб: Питер. 304 с.

Мэтьюз Д. 2016. Экология демократии. В поисках ведущей силы успешного будущего. М.: Центр книги Рудомино. 240 с.

Пол Р. 2015. Революиия в школе. Новое разрушение для разрушенной системы образования. М.: Питер. 208 с.

Розов Н.С. 2011. Колея и перевал: макросоциологические основания стратегий России в ХХІ веке. М.: РОССПЭН. 735 с.

Фуко М. 2008. О начале герменевтики себя. - Логос. № 2. С. 65-94.

Чернышов А.Г. 2013. Цена будущего. Тем, кто хочет (вы)жить. М.: Алгоритм. $352 \mathrm{c}$.

Честерфилд Ф.Д.С. 2010. Письма к сыну. М.: Рипол Классик. 416 с.

Ядов В.А., Магун В.С., Семенова В.В., Левада Ю.А., Шанин Т., Дубин Б., Данилов В., Олейников Д., Энговатов М.В. Отцы и дети. Поколенческий анализ современной России. 2005. М.: Новое литературное обозрение. 328 с.

CHERNYSHOV Aleksei Gennadsevich, Dr.Sci. (Pol. Sci.), Professor of the Chair of State and Municipal Management, Financial University under the Government of the Russian Federation (49 Leningradsky Ave, Moscow, Russia, 125993; ag555@mail.ru)

\section{PARENTS AS CITIZENS}

Abstract. The article attempts to analyze the phenomenon of the development of parenthood as a special social community of people. The author stresses the importance of turning a parent into a full-fledged citizen, able to fight for his rights, to form and defend creative development programs. In addition, the author suggests that there is a need for the formation of a global international civil parents' forum.

Keywords: parents, family, citizens, non-citizens, half-citizens, global parents' forum 